\title{
Assessing the long-term potential of fiber reinforced polymer composites for sustainable marine construction
}

\author{
Steve Kappenthuler ${ }^{1} \cdot$ Stefan Seeger $^{1}$ (D
}

Received: 7 November 2019 / Accepted: 22 January 2021 / Published online: 17 April 2021

(c) The Author(s) 2021

\begin{abstract}
Fiber reinforced polymer composites (FRPC) have gain rapid interest as light-weight and corrosion-resistant materials for various applications in marine infrastructure. Despite their advantages, FRPCs are still susceptible to other environmental factors present in the marine environment and manufactured mostly from non-renewable materials. This greatly affects the overall economic and environmental sustainability of such components. To determine the long-term suitability of various FRPCs for use in marine environments, this paper provides a holistic comparison of the performance of 16 FRPCs (four fiber types: glass, carbon, natural, basalt; and four polymer resins: epoxy, polyester, vinylester, thermoplastic) not only from a technical, but also from an economic, environmental and resource perspective. The resulting ranking not only assesses each material's long-term potential, but also provides a detailed overview of individual strengths and weaknesses. Although ranked the lowest of all materials, the partial renewability of the natural fiber composites makes them an interesting material in the longer term. Therefore, we use the framework to evaluate a number of approaches aimed at improving the overall performance of these composites.
\end{abstract}

Keywords Fiber reinforced polymer composites · Marine environment - Sustainable construction · Multi-criteria decisionmaking $\cdot$ Environmental impact $\cdot$ Resource availability

\section{Introduction}

Over the past decades, fiber reinforced polymer composites (FRPC) have been used more and more frequently in a wide range of applications in vehicles, aircraft, ships, and also civil infrastructure. More recently, FRPCs have also been used as external (fabric or plates) and internal (rebar) reinforcement for concrete structures and also as fully structural members (Fang et al. 2019; Shahawy et al. 1996; Uomoto et al. 2002). In marine environments, FRPCs have, in many cases, replaced more traditional materials such as aluminum or steel due to their high specific strength, excellent corrosion resistance, and, consequently, lower life cycle costs (Bai 2013; Graham-Jones and Summerscales 2015). Due to the artificial combination of two distinct materials (fiber and polymer resin), a plethora of different components with highly diverse and tailored mechanical properties can be

Stefan Seeger

sseeger@chem.uzh.ch

1 Department of Chemistry, University of Zurich, Winterthurerstrasse 190, 8057 Zurich, Switzerland constructed making the selection of appropriate material combinations a challenging task.

The most commonly employed FRPCs are reinforced either with carbon fibers (CF) or glass fibers (GF). In light of the growing importance of sustainability considerations in society, composites containing natural, plant-based fibers (NF) have been gaining increasing interest as low cost, environmentally friendlier alternatives (Pickering et al. 2016). Another fiber type that is seeing increasing usage is basalt fibers (BF) made from basaltic rock, which is a widely available resource in certain regions. These fibers require less preprocessing than GF and provide similar mechanical strength, thus presenting another viable alternative (Colombo et al. 2012; Fiore et al. 2015). While the durability of these materials under the harsh conditions present in the marine environment have been investigated extensively (Berges et al. 2016; Correia et al. 2006; Davies et al. 1996; Garcia-Espinel et al. 2015; Gassan and Andrzej 1999; Kootsookos and Mouritz 2004; Liu et al. 2006; Maslinda et al. 2017; Poodts et al. 2013; Tual et al. 2015; Wei et al. 2011; Yan et al. 2015), the comparability of this data is limited due to the wide amount of experimental parameters affecting 
the final results (Frigione and Lettieri 2018). Furthermore, existing performance evaluations focus solely on mechanical and durability aspects, thus failing to address the question whether the production, use, and disposal of such FRPCs is actually sustainable in the long term. To answer this question not only considerations of technical, but also economic and environmental and resource availability aspects need to be included.

In this paper, we present such an evaluation for the four previously mentioned fiber types used with four different polymer matrices, resulting in a total of 16 FRPC materials. For this, we apply a framework designed to provide a holistic evaluation of different construction materials for the use in sustainable construction to the specific case of marine construction. The framework builds on a ranking of materials according to their durability, economics of use, and environmental performance as well as the long-term availability of their raw materials (Kappenthuler and Seeger 2019). The resulting ranking of the different materials provides a detailed overview of the strengths and weaknesses of each material, and allows a further high-level prioritization of research areas which have a high potential to improve the performance of the individual materials.

This paper is structured as follows. First, the methodology of the ranking is explained and the different FRPCs that were evaluated are presented. This is followed by the results of the ranking, which was completed with experts from industry and academia. Finally, we specifically address the weaknesses of the renewable NF composites and briefly discuss those research areas offering the highest potential for improvement, allowing these materials to compete with the non-renewable alternatives.

\section{Methodology}

The results presented in this study are based on the application of a previously developed framework that ranks a set of materials according to the four categories of Durability, Economics \& Costs, Sustainability \& Environmental Impact (EI), and Future Availability. Each category consists of multiple attributes which are given a score from 1 to 5 (low-high) for each material according to a predefined scale. Aggregating the individual attribute scores using a Simple Additive Weighting process produces the final score for each material and enables the assessment of the material's overall potential. Furthermore, the individual scores provide an overview of each material's strengths and weaknesses, which enables a first high-level evaluation of the impact various material and policy developments may have on the performance of a material in a specific area. A detailed description of the framework is presented in Kappenthuler and Seeger (2019). In addition to the information provided there, case-specific adaptions are discussed in the following subchapters.

\subsection{Goal of ranking}

The goal of the presented study is to assess the potential of various FRPCs for the use as structural components for sustainable marine construction in the long-term future. The Durability attributes of the original framework were adapted to evaluate the durability of the composites exposed to the harsh marine environment, specifically the splash zone (See "Appendix"). The Future Availability attributes are evaluated for a timeframe of 50 years unless stated otherwise.

\subsection{Category and attribute weights}

A weighting factor is assigned to all categories and attributes according to their overall importance for achieving the stated goal (i.e., the use of the evaluated materials as structural components for sustainable marine construction in the long-term future). Attributes with a high, medium, or low importance are weighted with a factor of 3,2 , or 1 , respectively. These weights were defined together with experts from industry and academia.

As the main goal is to assess the long-term sustainability of the evaluated materials, Future Availability was given a higher weight. The immediate Economics \& Costs have a reduced effect on the long-term performance of materials, as the scores may change quickly in the wake of technological or regulatory developments. Thus, the weighting factor for this category was reduced. All categories, attributes, and the corresponding weighting factors are shown in Table 1.

\subsection{Definition of functional unit}

To compare the performance of the different composites used as structural materials, the functional unit (FU) was related to the materials' compressive strengths. For each composite, the FU was the weight of a $1 \mathrm{~m}$ long column with a square cross-section that is able to withstand a compressive load of $5000 \mathrm{kN}$ produced from the given composite. Consequently, the compressive strength of each FRPC determines the area of the cross-section and, thus, the volume of the entire column, which, in turn, determines the weight of the column.

\subsection{Material selection for ranking}

For this analysis, different materials were considered for the matrices and fibers of the composites. Material selection was intended to include not only the most commonly used materials, but also materials that exhibit favorable properties, but have so far not been applied widely in marine construction. 
Table 1 Categories, attributes, and respective weights used for ranking

\begin{tabular}{|c|c|}
\hline Category (weight) & Attribute (weight) \\
\hline Durability (2) & $\begin{array}{l}\text { Corrosion resistance (3) } \\
\text { Resistance to biological degradation (3) } \\
\text { Fatigue resistance (2) } \\
\text { Resistance to stress corrosion cracking (2) } \\
\text { UV resistance (1) } \\
\text { Moisture resistance (3) }\end{array}$ \\
\hline Economics and costs (1) & $\begin{array}{l}\text { Material costs (3) } \\
\text { Ease of manufacture (1) } \\
\text { Maintenance cost-vulnerability (3) } \\
\text { Maintenance cost—repairability (3) } \\
\text { Reaction to fire (2) } \\
\text { Resistance to fire (2) } \\
\text { Performance uncertainty (1) } \\
\text { Projected price development (1) }\end{array}$ \\
\hline Sustainability and environmental impact (2) & $\begin{array}{l}\text { Raw material renewability (2) } \\
\text { Recycling approach (3) } \\
\text { Impact of production on human health (2) } \\
\text { Impact of production on ecosystems (2) } \\
\text { Impact of production on resources (2) }\end{array}$ \\
\hline Future availability (3) & $\begin{array}{l}\text { Short-term raw material availability (2) } \\
\text { Long-term raw material availability (3) } \\
\text { Geographical distribution of reserves (3) } \\
\text { Potential for restrictive government regula- } \\
\text { tion (2) } \\
\text { Development of recycling infrastructure (3) } \\
\text { Projected growth of competing industries } \\
\text { (2) } \\
\text { Ease of production increase (1) }\end{array}$ \\
\hline
\end{tabular}

In a first step, existing textbooks on material science and engineering were analyzed to determine the generally accepted categories of composite materials that are used in engineering and construction (Ashby 2016; Graham-Jones and Summerscales 2015; Reuben 1994). To bring the number of materials down to a manageable level, materials were grouped into subcategories containing materials with very similar chemical compositions (ex. natural fibers, thermoplastics). Although the materials in such a subcategory may exhibit different properties depending on their exact composition, the differences will be significantly smaller than when compared to materials in other subcategories.

Materials which are almost exclusively used in mechanical engineering and not construction (such as technical ceramics) as well as recently developed materials for which little-to-no data exist were also removed. Finally, the list of candidate materials was discussed with several industry experts to ensure that no relevant materials were missing.

Glass fiber (GF), carbon fiber (CF), natural fiber (NF), and basalt fiber (BF) were included in the ranking. For the matrices, three different thermoset resins [Epoxy (E),
Polyester (PE), and Vinylester (VE)] as well as a general thermoplastic (TP) polymer were included. Each fiber and matrix combination was evaluated as a single material. The composite was assumed to contain continuous fibers at a fiber volume fraction of 0.5 . As the mechanical properties of FRPC components depend greatly on the exact form of manufacturing (ex. pultrusion, winding, hand-layup, etc.), an average value of compressive strength (established through discussions with industry experts) was assumed for all composites (Table 3). Finally, to enable accurate EI calculations, a specific material needed to be chosen for the natural fibers (i.e., Jute) as well as the thermoplastic resin (i.e., polycarbonate).

\subsection{Data collection}

The main source of data for completion of the ranking were discussions with experts from industry and academia, as well as data from technical reports, material databases, and scientific literature. The individual experts completed the ranking for all materials and were asked to explain their 
reasoning behind each score. If the scores given for a specific attribute varied by only 1 point, the average score was chosen as the final score. If the scores varied by more than 1 point, further investigation into the literature was conducted, to conclude which score was appropriate. Six experts from academia and industry completed the ranking.

\section{Results and discussion}

The results of the material ranking are displayed in Table 2 . CF composites achieved the overall highest scores mainly due to their high chemical resistance and mechanical strength leading to the highest Durability, Economics, and Sustainability scores for each respective CF composite. The Future Availability scores are almost identical for all materials, as the main raw material of concern is petroleum or natural gas for the production of the polymer matrices. GF and BF composites perform very similarly with the BF composites achieving slightly higher Durability and Sustainability scores. However, the values for BF are largely based on estimates, as they have not been extensively used in construction to date (resulting in a lower Economics score compared to GF). Consequently, further research will be required to determine the overall performance of the BF composites in marine environments more precisely. Despite being the only fiber type that can be produced from renewable sources, the NF composites are the lowest ranked materials in this analysis. This is due to their low-moisture resistance and biological resistance, as well as their relatively weak mechanical properties. While these composites may be very promising for certain applications where cheap, light-weight components are required, they are not well suited for the use as structural materials in marine environments without further protection and improving their mechanical properties. The individual attribute scores will be discussed for all analyzed composites in the following sections.

\subsection{Durability}

Aside from the NF composites, all materials have a high Durability score with the main weaknesses being UV and Moisture Resistance.

All FRPCs are inherently corrosion-resistant and except for the NF composites are immune to degradation by marine organisms (score 5). The natural fibers contained in the polymer matrix could be degraded by marine organisms if they are exposed to the surrounding environment, through for instance cracking of the matrix (score 4).

The fatigue resistance of FRPCs is determined mainly by the fiber type and content. GF, BF, and NF can suffer from fatigue damage. However, if stresses are kept below the fatigue limit (which can be accurately predicted), the polymer matrix will stretch elastically leading to an infinite fatigue life (score 3) (Kulkarni et al. 2003). CFs are more resistant to fatigue than the other fiber types (score 4) (Colombo et al. 2012).

For the thermoset matrices, UV radiation mainly presents a problem concerning the aesthetics, as the rays can only penetrate about $1 \mathrm{~mm}$ into the polymer. This leads to a discoloring and roughening of the surface layer, but does not strongly affect the mechanical properties of the composite if the entire component is thick enough $(>10 \mathrm{~mm}$ ) (Correia et al. 2006; Karbhari 2007). As the degraded surface can be more easily removed by mechanical forces which would lead to the exposure of the polymer layer beneath it, UV rays can lead to a more rapid degradation of the composite (score 3 for GF, CF, and BF with $\mathrm{E}, \mathrm{PE}$, and VE matrix). TP is more vulnerable to UV degradation. It becomes brittle during exposure and can completely degrade over time. The time of degradation can be controlled by increasing the composites thickness (score 2 for GF, CF, and BF). As NFs are degraded through exposure to UV rays, the scores were reduced for the NF composites (score 2 for $\mathrm{E}, \mathrm{VE}$, and score 1 for TP) (Yan et al. 2015).

The most crucial attribute determining the Durability of FRPCs in the marine environment is their moisture resistance. The polymer matrices of these composites can absorb water which can lead to swelling and degradation of the polymer. Swelling of the matrix leads to degradation of the fiber-matrix interface and thus decreases the composites mechanical properties. In general, VE has the best properties of all the matrices as it only absorbs little moisture (Figliolini and Carlsson 2013). This also limits the amount of moisture that could potentially reach the imbedded fibers (score 4 for GF and BF). For CFs, however, the CF-VE bond is inherently weak and further decreases with even slight swelling of the matrix (score 2) (Figliolini and Carlsson 2014; Latif et al. 2019).

Although the individual behavior is not exactly the same the $\mathrm{E}$ and TP matrices were seen as similar concerning moisture resistance. Swelling moderately reduces the mechanical properties of composites with these matrices. GF and BF fibers may degrade slightly over an extended period of time (score 3), while CFs are not affected (score 4) (Ramirez et al. 2008).

PE, being one of the cheapest resin materials, absorbs comparably large amounts of water and is also susceptible to leaching. When used in combination with GF and BF, components should not be used in marine environments without a protective coating if longer lifetimes are desired (score 2). For CF, this is less critical (score 3 ).

For NF composites, the fibers themselves completely degrade over time if exposed to moisture. Therefore, even if the matrix only absorbs a small amount of water, 
Table 2 Ranking results including attribute, category, and total scores of analyzed FRP composites

\begin{tabular}{|c|c|c|c|c|c|c|c|c|c|c|c|c|c|c|c|c|c|}
\hline & \multicolumn{4}{|c|}{ Glass Fiber } & \multicolumn{4}{|c|}{ Carbon Fiber } & \multicolumn{4}{|c|}{ Natural Fiber } & \multicolumn{4}{|c|}{ Basalt Fiber } \\
\hline & & E & $\mathrm{PE}$ & $\mathrm{VE}$ & TP & E & $\mathrm{PE}$ & $\mathrm{VE}$ & TP & $\mathbf{E}$ & $\mathrm{PE}$ & $\mathrm{VE}$ & TP & $\mathbf{E}$ & PE & VE & TP \\
\hline \multirow{7}{*}{ 点 } & Corrosion Resistance & 5 & $\overline{5}$ & $\overline{5}$ & 5 & $\overline{5}$ & 5 & $\overline{5}$ & $\overline{5}$ & $\overline{5}$ & $\overline{5}$ & 5 & 5 & 5 & 5 & $\overline{5}$ & $\overline{5}$ \\
\hline & $\begin{array}{c}\text { Resistance to Biological } \\
\text { Degradation }\end{array}$ & 5 & 5 & 5 & 5 & 5 & 5 & 5 & 5 & 4 & 4 & 4 & 4 & 5 & 5 & 5 & 5 \\
\hline & Fatigue Resistance & 3 & 3 & 3 & 3 & 4 & 4 & 4 & 4 & 3 & 3 & 3 & 3 & 3 & 3 & 3 & 3 \\
\hline & $\begin{array}{l}\text { Resistance to Stress } \\
\text { Corrosion Cracking }\end{array}$ & 3 & 3 & 3 & 3 & 5 & 5 & 5 & 5 & 2 & 2 & 2 & 2 & 4 & 4 & 4 & 4 \\
\hline & UV Resistance & 3 & 3 & 3 & 2 & 3 & 3 & 3 & 2 & 2 & 2 & 2 & 1 & 3 & 3 & 3 & 2 \\
\hline & Moisture Resistance & 3 & 2 & 4 & 3 & 4 & 3 & 2 & 4 & 1 & 1 & 1 & 1 & 3 & 2 & 4 & 3 \\
\hline & Category Score & 3.92 & 3.69 & 4.15 & 3.85 & 4.54 & 4.31 & 4.08 & 4.46 & 3.00 & 3.00 & 3.00 & 2.92 & 4.08 & 3.85 & 4.31 & 4.00 \\
\hline
\end{tabular}

\begin{tabular}{|c|c|c|c|c|c|c|c|c|c|c|c|c|c|c|c|c|}
\hline Material Costs & 4 & 3 & 3 & 2 & 5 & 5 & 5 & 4 & 2 & 1 & 1 & 1 & 4 & 3 & 3 & 2 \\
\hline Ease of Manufacture & 4 & 4 & 4 & 3 & 4 & 4 & 4 & 3 & 4 & 4 & 4 & 3 & 4 & 4 & 4 & 3 \\
\hline $\begin{array}{l}\text { Maintenance Cost - } \\
\text { Vulnerability }\end{array}$ & 3 & 3 & 3 & 3 & 3 & 3 & 3 & 3 & 3 & 3 & 3 & 3 & 3 & 3 & 3 & 3 \\
\hline $\begin{array}{l}\text { Maintenance Cost - } \\
\text { Repairability }\end{array}$ & 4 & 4 & 4 & 3 & 4 & 4 & 4 & 3 & 4 & 4 & 4 & 3 & 4 & 4 & 4 & 3 \\
\hline Reaction to Fire & 3 & 2 & 3 & 1 & 3 & 2 & 3 & 1 & 1 & 1 & 1 & 1 & 3 & 2 & 3 & 1 \\
\hline Resistance to Fire & 3 & 3 & 3 & 1 & 3 & 3 & 3 & 1 & 1 & 1 & 1 & 1 & 3 & 3 & 3 & 1 \\
\hline $\begin{array}{l}\text { Performance } \\
\text { Uncertainty }\end{array}$ & 3 & 3 & 3 & 3 & 3 & 3 & 1 & 3 & 1 & 1 & 1 & 1 & 1 & 1 & 1 & 1 \\
\hline $\begin{array}{c}\text { Projected Price } \\
\text { Developments }\end{array}$ & 2 & 2 & 2 & 2 & 3 & 3 & 3 & 3 & 3 & 3 & 3 & 3 & 2 & 2 & 2 & 2 \\
\hline Category Score & 3.38 & 3.06 & 3.19 & 2.25 & 3.63 & 3.50 & 3.50 & 2.69 & 2.44 & 2.25 & 2.25 & 2.00 & 3.25 & 2.94 & 3.06 & 2.13 \\
\hline
\end{tabular}

\begin{tabular}{|c|c|c|c|c|c|c|c|c|c|c|c|c|c|c|c|c|c|}
\hline $\begin{array}{l}\text { Raw Material } \\
\text { Renewability }\end{array}$ & 1 & 1 & 1 & 1 & 1 & 1 & 1 & 1 & 3 & 3 & 3 & 3 & 1 & 1 & 1 & 1 \\
Recycling Approach & 2 & 2 & 2 & 2 & 2 & 2 & 2 & 2 & 2 & 2 & 2 & 2 & 2 & 2 & 2 & 2 \\
\hline $\begin{array}{c}\text { Impact of Production on } \\
\text { Human Health }\end{array}$ & 3 & 2 & 4 & 2 & 5 & 5 & 5 & 4 & 1 & 1 & 2 & 1 & 3 & 3 & 4 & 3 \\
$\begin{array}{c}\text { Impact of Production on } \\
\text { Ecosystems }\end{array}$ & 3 & 2 & 4 & 3 & 5 & 4 & 5 & 5 & 1 & 1 & 2 & 1 & 3 & 2 & 4 & 3 \\
\hline $\begin{array}{c}\text { Impact of Production on } \\
\text { Resources }\end{array}$ & 4 & 2 & 5 & 2 & 4 & 3 & 5 & 3 & 1 & 1 & 2 & 1 & 5 & 3 & 5 & 3 \\
\hline Category Score & 2.55 & 1.82 & 3.09 & 2.00 & 3.27 & 2.91 & 3.45 & 2.91 & 1.64 & 1.64 & 2.18 & 1.64 & 2.73 & 2.18 & 3.09 & 2.36 \\
\hline
\end{tabular}

\begin{tabular}{|c|c|c|c|c|c|c|c|c|c|c|c|c|c|c|c|c|}
\hline Short-Term Availability & 3 & 3 & 3 & 3 & 3 & 3 & 3 & 3 & 3 & 3 & 3 & 3 & 3 & 3 & 3 & 3 \\
\hline Long-Term Availability & 4 & 4 & 4 & 4 & 4 & 4 & 4 & 4 & 4 & 4 & 4 & 4 & 4 & 4 & 4 & 4 \\
\hline $\begin{array}{c}\text { Geographical } \\
\text { Distribution of Reserves }\end{array}$ & 5 & 5 & 5 & 5 & 5 & 5 & 5 & 5 & 5 & 5 & 5 & 5 & 5 & 5 & 5 & 5 \\
\hline $\begin{array}{l}\text { Potential for Restrictive } \\
\text { Government Regulation }\end{array}$ & 4 & 4 & 4 & 4 & 4 & 4 & 4 & 4 & 4 & 4 & 4 & 4 & 4 & 4 & 4 & 4 \\
\hline $\begin{array}{c}\text { Development of } \\
\text { Recycling Infrastructure }\end{array}$ & 3 & 3 & 3 & 3 & 4 & 4 & 4 & 4 & 3 & 3 & 3 & 3 & 3 & 3 & 3 & 3 \\
\hline $\begin{array}{l}\text { Projected Growth of } \\
\text { Competing Industries }\end{array}$ & 3 & 3 & 3 & 3 & 2 & 2 & 2 & 2 & 3 & 3 & 3 & 3 & 3 & 3 & 3 & 3 \\
\hline $\begin{array}{c}\text { Ease of Production } \\
\text { Increase }\end{array}$ & 3 & 3 & 3 & 3 & 3 & 3 & 3 & 3 & 2 & 2 & 2 & 2 & 3 & 3 & 3 & 3 \\
\hline Category Score & 3.69 & 3.69 & 3.69 & 3.69 & 3.75 & 3.75 & 3.75 & 3.75 & 3.63 & 3.63 & 3.63 & 3.63 & 3.69 & 3.69 & 3.69 & 3.69 \\
\hline Total Score & 3.42 & 3.14 & 3.59 & 3.13 & 3.81 & 3.65 & 3.73 & 3.58 & 2.82 & 2.80 & 2.94 & 2.75 & 3.49 & 3.26 & 3.62 & 3.24 \\
\hline Rank & 8 & 11 & 5 & 12 & 1 & 3 & 2 & 6 & 14 & 15 & 13 & 16 & 7 & 9 & 4 & 10 \\
\hline
\end{tabular}


the mechanical properties of the component will decrease greatly over time (score 1 for all matrices) (Yan et al. 2014).

The susceptibility of the composites to SCC (defined in this study as damaged caused through the combined effect of mechanical stresses and chemical attack in seawater, see "Appendix") is similar to the moisture resistance rating, as it is dependent on the propensity of the fibers to be degraded by moisture if mechanical forces cause cracks in the surrounding polymer matrix. CFs will not be degraded (score 4), while NFs will degrade rather quickly (score 2). GFs are slightly more resistant, but will also degrade over time if exposed to moisture (score 3) (Affolter et al. 2018). Not much data exist on the performance of BFs. Some experts believe them to be immune, while others consider their behavior similar to GFs (score 4). Further research would allow a more exact ranking of this fiber type.

\subsection{Economics and costs}

The scores for most analyzed composites are rather low in this category as they are relatively susceptible to mechanical damage as well as fire and have not been used extensively for large-scale structural components in the marine environment.

While CF composites are the most expensive per $\mathrm{kg}$, their superior mechanical properties greatly reduce the weight of one FU and thus make them the cheapest material for this evaluation. The opposite occurs with the NF composites, which are the cheapest per kg but due to the low mechanical strength require such a large amount of material for the production of $1 \mathrm{FU}$, which leads to the highest costs per FU.

There exist various techniques for the manufacture of FRPC components which depend mainly on the type of matrix and not the fiber type. Composites with thermoset matrices can be constructed rather easily by hand-layup. However, the quality of such components can be very variable and needs to be done carefully to achieve good results. For highest quality, large-scale composites, layup can be done with machines followed by curing in an autoclave. Another manufacturing technique, vacuum-assisted resin transfer molding (VARTM) enables the production of large parts in any shape (provided an appropriate mold is manufactured) with a high quality and curing at room temperature. In general, it may be more appropriate to manufacture composite components in a factory, but on-site fabrication is also possible (score 4 for all $\mathrm{E}, \mathrm{VE}$, and PE composites). Thermoplastics, on the other hand, need to be heated to allow for the forming and bonding of a composite component. Therefore, TP composites are manufactured in a factory where the regular application of heat does not present a problem (score 3 for all TP composites).

FRPCs are rather sensitive to damage from impact as this can cause delamination. This damage can occur inside the composite and not be visible from the outside. However, due to the structure of composite materials, damage remains rather local. A crack in the matrix is stopped when it reaches the next fiber interface. In general, TP matrices are more ductile and can absorb larger impact forces than thermosets, but the overall ranking score was not changed as the general behavior is very similar (score 3 for all composites).

If damaged, FRPCs can be replaced on-site by cutting out the damaged part and applying a new composite patch with fresh resin. This can restore a certain amount of strength. However, the fibers are cut at interface between the old and new matrix, decreasing the strength and durability of the component. The on-site application of thermoset resins is simpler than that of thermoplastics. Thus, mechanical properties can be restored more completely when repairing thermoset composites (score 4 for all $\mathrm{E}, \mathrm{PE}$, and $\mathrm{V}$ composites and score 3 for all TP composites).

The flammability classes used to determine the composites' Reaction to Fire are dependent on the polymer material. $\mathrm{E}$ and VE composites correspond to class $\mathrm{C}$, while PE composites fall into class D (Correia et al. 2010; Hertzberg 2005; Nguyen et al. 2013). As no data could be found for TP composites, it was assumed that they would fall into the lowest category. All NF composites also fall into this class, as the fibers themselves are combustible (Seefeldt 2012).

For the NF composites, this also leads to the lowest score for Resistance to Fire, as both the polymer matrix and the fibers are flammable, but burn at different rates and temperatures which makes it exceedingly difficult to predict their burning behavior.

The Resistance to Fire of the GF, CF, and BF composites is also limited by the relatively low-degradation temperature of the polymer matrix. However, intensive research into the burning behavior of different matrix materials has made it possible to more or less accurately predict the burn and char rate of these materials (Correia et al. 2015). Char formation on the surface of a component protects the underlying layer of material from the heat for a certain amount of time, thus increasing the lifetime of the component in a fire. Furthermore, it has been shown that with a proper design, composite components can retain their structural integrity during a fire for an extended period of time if necessary (score 3 for E, PE, and VE composites) (Correia et al. 2015). TP melts and degrades at low temperatures and will not be able to withstand a fire for very long. Even if the fibers remain intact as the matrix material melts away, the composite will lose all mechanical strength (score 1 for all composites).

Concerning Performance Uncertainty, GF and CF composites are the only composites that have been used extensively in the construction of small and large vessels to date. However, the use as structural components in larger offshore structures has not been fully established to date (score 3). An exception are $\mathrm{CF}-\mathrm{VE}$ composites which, due to the 
mentioned weak interfacial bond, have not found any significant application in marine environments (score 1).

The same is true for NF and BF composites. Although tests concerning the durability in humid environments have been conducted (Alhuthali and Low 2015; Fiore et al. 2016; Liu et al. 2006; Maslinda et al. 2017; Wei et al. 2011; Yan et al. 2015), and the assumption by most experts that BF will perform similarly to GF in marine use, the real-life performance uncertainty for these composites is very high (score 1 for all matrices).

The Projected Price Developments are dependent on the change in prices of the fibers as well as the polymer matrices. In general, it is expected that prices for petroleumbased products will increase in the future. This will also be affected by governments and politics by influencing the price of crude oil through tariffs, taxes, and trade restrictions.

Considering the already low prices for GF, it is very unlikely that the production of GF will become any cheaper in the future. The same is true for BFs, which are even cheaper to produce (score 2 for all GF and BF composites).

The processes for $\mathrm{CF}$ production and CF composite production are, however, still being further optimized. Nevertheless, CF prices have not decreased strongly in the past years despite predictions that they could reach the price of GF at some point. Therefore, although a slight decrease in price is possible with further development of production and processing technologies, it is not expected that the prices for $\mathrm{CF}$ will decrease greatly in the future (score 3 for all matrices).

Finally, as NF composites are currently still being produced on a relatively small scale, a large increase in production volumes which is expected in the longer term for these materials may lead to economies of scale and thus reduced production costs for manufacturers. Further process developments may also decrease the production costs for the fibers (score 3 for all matrices).

\subsection{Sustainability and environmental impact}

Aside from those containing NF (which contain 50\% fibers that are considered renewable, score 3 ), none of the analyzed composites is produced from renewable raw materials (score 1). Further decreasing the overall Sustainability scores for all composites are the very low recycling rates. Currently, no technology exists to fully recycle FRPCs, especially with a thermoset matrix, as the covalent bonds that form upon curing of the resin cannot be easily broken once the polymer has hardened. Therefore, downcycling is the only disposal option beside incineration or landfilling. For downcycling, the composite is ground into fine powder and used as filler in concrete or other composites. Although it may be possible to melt thermoplastic matrices and recover the fibers, this is currently only done on a laboratory scale and the mechanical properties of the recovered fibers are strongly degraded (Job et al. 2016; Oliveux et al. 2015). In Europe, downcycling is more common than in the US where incineration and landfilling are still the major disposal options (score 2 for all composites).

The EIs of the individual composites were calculated using data from the Ecoinvent 3.3 database, which was adapted with data from literature to reflect the exact fiber and matrix type, as well as the fiber volume fraction specified earlier [information on the individual calculations can be found in the Supplementary Information (SI)]. Overall, the $\mathrm{CF}$ composites have the lowest EI/FU followed by the BF composites which are slightly better than the GF composites (Table 3). The lowest ranking materials are the NF composites. This is due to the relatively low mechanical strength of the NFs leading to a large amount of material required for a FU. Per kg, the NF composites produce a lower EI than those with GF. Contrarily, the CF composites have an EI of production that is almost three times higher per $\mathrm{kg}$ than that of the corresponding GF composites.

Concerning the polymer matrices, they all have very similar impacts per $\mathrm{kg}$. However, factoring in the contribution to the overall compressive strength, VE performs best, followed by E, PE, and TP if ranked in relation to the FU.

\subsection{Future availability}

The future availability scores are very similar for all analyzed composites, as petroleum (or alternatively natural gas) required for production of the polymer matrices as well as the CFs is the only critical raw material. Table 4 shows the availability and concentration values for these resources.

The petroleum-based materials (resins and CF) are also the reason for the slightly reduced Government Regulation score of all composites (score 4). In the past, governments have already banned certain chemicals from being used, after it had been shown that they can have severe negative effects on human health or the environment. Although the substances used for the manufacture of the polymers and CFs which are being analyzed in this ranking have been used intensively for years, there is a small possibility that more stringent environmental regulations will restrict their use. Furthermore, as petroleum is a limited resource, there is a chance that governments may impose regulations to control its use, in light of increasing scarcity. Most likely however the use of petroleum as a fuel will be restricted before the manufacture of high-quality products, such as polymers, is affected.

Concerning the materials required for the production of GF and BF, there is no reason why governments should forbid any specific mining practices as the rock mining which takes place does not involve any strongly hazardous chemicals. 
Table 3 Mechanical, economic, and EI data of analyzed FRP composite materials (based on data from van Vuure et al. (2015), industry sources, the MaterialUniverse database provided by Granta Design (Granta Material Intelligence 2018), and own EI calculations shown in SI)

\begin{tabular}{|c|c|c|c|c|c|c|c|c|}
\hline \multirow[t]{2}{*}{ Fiber } & \multirow[t]{2}{*}{ Matrix } & \multirow{2}{*}{$\begin{array}{l}\text { Compressive } \\
\text { strength (MPa) }\end{array}$} & \multirow[t]{2}{*}{$\mathrm{kg} / \mathrm{FU}$} & \multirow[t]{2}{*}{ Price $(\$ / F U)$} & \multicolumn{4}{|c|}{ Environmental impact (Pt/FU) } \\
\hline & & & & & Human health & Ecosystems & Resources & Total \\
\hline \multirow[t]{4}{*}{ Glass Fiber } & Epoxy & 600 & 15.96 & 485.7 & 4.29 & 1.72 & 3.30 & 9.32 \\
\hline & Polyester & 420 & 22.59 & 572.5 & 5.51 & 2.69 & 4.18 & 12.38 \\
\hline & Vinyl ester & 600 & 15.08 & 573.2 & 3.70 & 1.55 & 2.97 & 8.22 \\
\hline & Thermoplastic & 420 & 22.47 & 671.3 & 5.77 & 2.52 & 4.13 & 12.43 \\
\hline \multirow[t]{4}{*}{ Carbon Fiber } & Epoxy & 1700 & 4.52 & 165.1 & 2.81 & 1.21 & 3.37 & 7.39 \\
\hline & Polyester & 1200 & 6.33 & 223.7 & 2.94 & 1.51 & 4.06 & 8.51 \\
\hline & Vinyl ester & 1700 & 4.21 & 168.1 & 2.01 & 0.98 & 2.86 & 5.85 \\
\hline & Thermoplastic & 1200 & 6.29 & 229.6 & 3.07 & 1.47 & 4.12 & 8.66 \\
\hline \multirow[t]{4}{*}{ Natural Fiber } & Epoxy & 150 & 44.25 & 942.8 & 10.35 & 5.49 & 8.63 & 24.47 \\
\hline & Polyester & 105 & 62.38 & 1106.7 & 12.35 & 8.73 & 10.23 & 31.32 \\
\hline & Vinyl ester & 150 & 40.75 & 1084.0 & 8.07 & 4.81 & 7.34 & 20.21 \\
\hline & Thermoplastic & 105 & 61.90 & 1294.6 & 13.37 & 8.11 & 10.15 & 31.63 \\
\hline \multirow[t]{4}{*}{ Basalt Fiber } & Epoxy & 600 & 16.46 & 501.0 & 3.83 & 1.68 & 3.18 & 8.69 \\
\hline & Polyester & 420 & 23.30 & 590.6 & 4.87 & 2.63 & 4.01 & 11.51 \\
\hline & Vinyl ester & 600 & 15.58 & 592.2 & 3.27 & 1.52 & 2.85 & 7.64 \\
\hline & Thermoplastic & 420 & 23.18 & 692.6 & 5.12 & 2.46 & 3.96 & 11.55 \\
\hline
\end{tabular}

Table 4 Availability and geographical concentration of petroleum and natural gas (calculated with data from BP 2018)

\begin{tabular}{llll}
\hline Resource & $\begin{array}{l}\text { Short-term avail- } \\
\text { ability }\end{array}$ & $\begin{array}{l}\text { Long-term avail- } \\
\text { ability }\end{array}$ & $\begin{array}{l}\text { Geo- } \\
\text { graphical } \\
\text { distribu- } \\
\text { tion }\end{array}$ \\
& $\begin{array}{l}\text { (reserves/production } \\
\text { ratio) }\end{array}$ & $\begin{array}{l}\text { (resource/production } \\
\text { ratio) }\end{array}$ & $\begin{array}{l}\text { HH Index } \\
\text { of reserve } \\
\text { concentra- } \\
\text { tion }\end{array}$ \\
\hline Petroleum & 50.7 & 128 & 957 \\
Natural Gas & 52.8 & 115 & 998 \\
\hline
\end{tabular}

The long-term recycling potential of all composites (except for the CFs) is rather moderate. While the percentage of composites which will be downcycled in the future will increase, the step toward full recycling is very unlikely for GF, NF, and BF, especially with the matrices investigated here. The processes which are currently running on pilot plant scale for the full recycling of continuous fiber composites involve pyrolysis or chemical treatment to dissolve the matrix. As these methods are extremely aggressive, the fibers degrade to a point where they cannot be used in the same applications again. For GF and BF, additionally, the price of production is very low and, therefore, the pressure to develop new recycling methods is also not very high. A promising approach for these fibers is to use chopped composite pieces as feed for cement kilns. The high calorific value of the resins provides heat for clinker production, while the mineral content of the fibers (calcium carbonate, alumina, and silica) is recycled into cement clinker. Thus, this can be seen as a type of cross material recycling. However, full recycling of long GF and BF for reuse in composites will not be possible in the foreseeable future (score 3 ).

For NF, the possibility of composting would mean that they could be considered as fully recycled. However, as mentioned, it is not possible to remove the fibers from the polymer matrices and, therefore, even composites with NFs will be treated in the same way as those with GF and BF making downcycling the only option (score 3 ). A possibility for full recycling would be the development of fully biodegradable, bio-based composites using a matrix which was also produced from biological sources. However, these biobased plastics are currently not durable enough to be used in structural applications (Le Duigou et al. 2009).

For CF composites, full recycling is potentially possible (score 4). CFs can withstand the aggressive processes for removal of the matrix material without being fully degraded. Nevertheless, currently, the recycled CFs lose around $50 \%$ of their strength during their recycling process, so they cannot replace virgin fibers. However, further research is ongoing to improve this process and retain a larger proportion of the fibers' mechanical strength (Bhat et al. 2017; Job et al. 2016; Oliveux et al. 2015). An additional approach which has been proposed is the development of new thermoset resins where the covalent bonds which form upon curing can be selectively broken under specific conditions which do not affect the integrity of the fibers contained in the polymer. This is 
currently only being investigated in the lab and is still a long way from commercial production.

Whether competition from other industries will be significant in the future is uncertain for all but the CF composites. The construction industry is not yet a major user of CF composites accounting for only $5 \%$ of total demand. The three largest industries are aerospace and defense (30\%), automotive $(22 \%)$, and wind turbines (13\%). Demand is expected to increase strongly for all these sectors, for instance due to increasing pressure from governments and also society for lower emission vehicles requiring light-weight alternatives to steel. Demand from the construction industry is still far below the expected potential. This is mostly due to the high price of CF composites compared to steel and in some countries building code requirements limiting the use of structural FRPC components. However, even with increasing demand growth in the construction sector, it is still expected to remain a rather small percentage of global CF composite demand in the future. In the past, it has already happened that a strong increase in CF demand from the aerospace industry caused a scarcity in the market for other segments. It is likely that this will occur again in the future despite the addition of significant production capacity by producers (score 2) (Das et al. 2016; Witten et al. 2016).

The main concern for the GF, NF, and BF composites comes from the use of oil for the manufacture of the matrix material. Currently, only a small percentage of raw oil is used for the manufacture of high value chemicals and plastics, while the main use is as fuel. This distribution will definitely shift further toward the chemical and plastic sector as the resource becomes scarcer. The global demand for plastic is expected to increase rapidly, especially due to economic development in emerging countries. As composite resins only account for a small part of the overall plastics and chemical industry, it may be possible that in the long-term future, the limited petroleum resources are diverted to produce other products. For the use of the FRPCs themselves, no strong competition is expected for these fiber types.

The transport and construction industries are the major consumers of GF composites. Each sector is responsible for about one-third of total demand. The demand from the transport industry for light-weight GF components will likely increase in the future. The construction industry is also expected to be one of the strongest growing demand sources as more and more building codes are adapted to allow the replacement of more traditional materials such as steel with GF composites for certain applications (score 3) (Witten et al. 2016).

BF composites serve mainly the same markets as GF composites. In general, the use of BF is currently still limited compared to GF or $\mathrm{CF}$, as it is a relatively new material. The main demand growth is expected from similar industries as for GF composites which are the transport and construction industries. Depending on the results of further research on the durability of these fibers, the marine industry may also become a major customer. As the raw materials for the production of BF and GF are abundantly available around the globe, there should not be any large competition for these materials from the different industries (score 3 ).

For NF composites, the largest market is currently the automobile sector. As mentioned, it is expected that this sector will continue to grow at above average rate and remain the main demand driver for natural fiber composites. The construction industry is the second largest user of natural fiber composite materials and is also expected to exhibit a high level of demand growth in the coming years (score 2) (Lucintel 2011; O'Dea 2015).

Significantly increasing global production levels will be most challenging for NF composites. The manufacture of NF for the use in polymer composites is rather new and a strong increase in production requires a scale-up of the current process involving a certain extent of technological development. Furthermore, the supply of plants for production of fibers would also need to be increased (score 2).

In the short term, CF, GF, and BF supply and demand forecasts are more or less balanced. However, it is already expected that more capacity will need to be installed to meet longer term demand (Das et al. 2016). Therefore, for a major increase to multiple levels of today's production, new facilities would be required (score 3). While the technology for manufacturing $\mathrm{CF}$ and GF is mature, the large-scale manufacture of $\mathrm{BF}$ is comparatively new. However, the process is very similar to the manufacture of GF (Azrague et al. 2016). Thus, it can be assumed that scale-up should not be such a big issue and can profit from the maturity of the GF production process.

Increasing the supply of polymer resins would not present an issue. The petroleum industry would have the capacity increase production if it is required and the chemical industry in turn would also be able to increase the production of the polymer resins. The technologies for the production of the thermoset and thermoplastic resins are also mature and already today produce at extremely large scales.

\subsection{Improving NF composite performance}

As can be seen in Table 2, the NF composites, which are promising materials from an availability perspective and have the lowest costs and EI per kg, achieve the lowest scores of all composites mainly due to their low mechanical strength which leads to the largest amount of material (in $\mathrm{kg}$ ) required for the production of $1 \mathrm{FU}$. While they also suffer from low-moisture resistance and high flammability, these weaknesses are also critical for the other fiber types. Therefore, focusing specifically on increasing the strength of these NF composites would be highly beneficial for their overall 
Table 5 Effect of improving NF composite properties on overall ranking (red and green ranks represent a decrease resp. increase in rank)

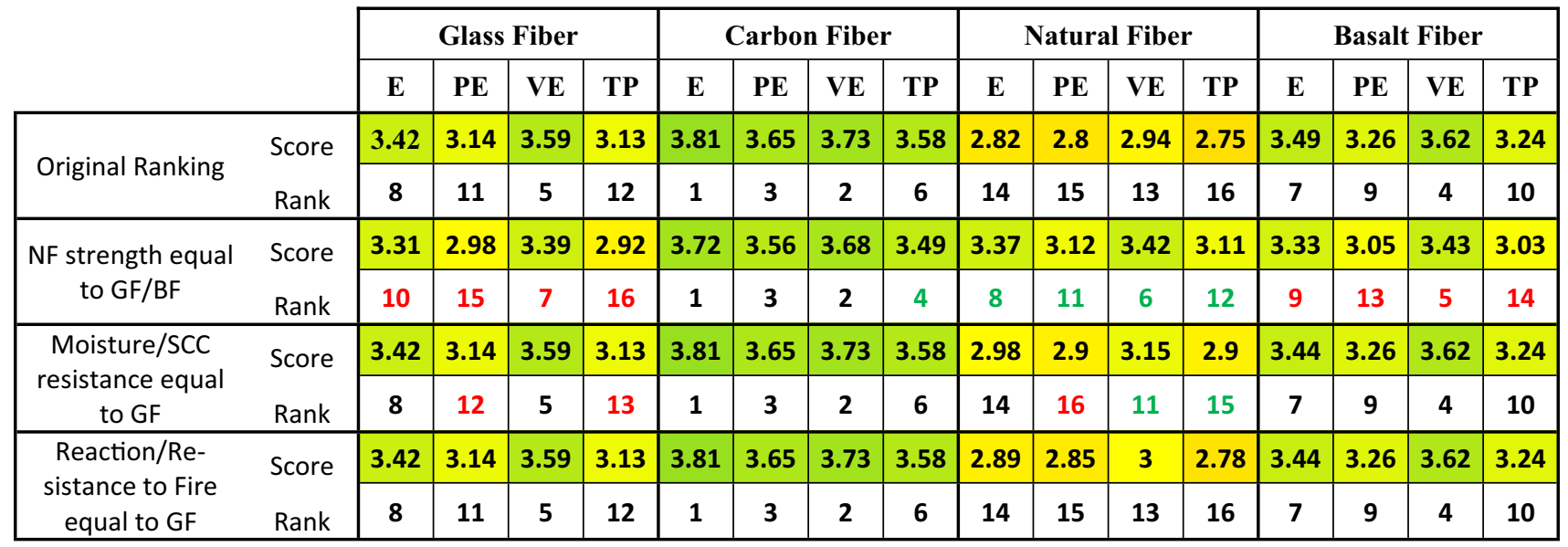

performance as this would increase their scores for the material cost and EI attributes. This is illustrated in Table 5 which shows how the NF composites would rank if their properties were increased to values comparable with the other composites. If the compressive strength of the NF composites could be increased to the level of the corresponding GF/BF composites, they would be ranked higher than both other fiber types for all matrices except VE, despite still suffering from the other mentioned weaknesses. CF composites remain superior and it is very unlikely that NF composites will ever reach similar mechanical properties as CF composites. If the moisture and, consequently, the SCC resistance of the NF composites could be increased to the values of the corresponding GF or even BF composites, some of the NF composites would achieve an overall slightly higher rank. However, they would still remain the lowest ranked fiber option for each individual matrix material. Increasing the reaction to fire and resistance to fire attributes would have the smallest effect, as only the scores, but not the ranks would be increased.

A major issue affecting the mechanical strength of NF composites is the low-bonding strength between the polar fibers and non-polar polymer matrices. Various physical and chemical surface treatments have been investigated to alter the fiber surface and increase the strength of the interfacial bond (Pickering et al. 2016; Ramesh et al. 2017; Sun 2018). While these treatments have been shown to increase the mechanical strengths of the resulting NF composites, it must be kept in mind that the increased amount of energy (for physical treatments) and use of potentially harmful substances (for chemical treatments) will also increase the EI of production per $\mathrm{kg}$. However, if the increase in strength is sufficient, the EI per FU of NF composites could nevertheless be decreased even to below the value of GF production (Wu et al. 2018).

\section{Conclusion}

This paper provides a holistic overview of the strengths and weaknesses of different fiber reinforced polymer composites used as structural components for marine construction. Overall, the best ranked materials are the CF composites followed by BF and GF composites. The lowest scores were achieved by NF composites mainly due to their low mechanical strength and lower chemical resistance. Concerning the matrix material, E and VE show a similar performance followed by the cheaper and less-resistant PE and TP resins. Using the results from the presented ranking, the main weaknesses of the NF composites were discussed and the improvement of mechanical strength was identified as the most promising development area to increase the overall performance of these composites. Naturally, there exist many further research areas aiming at improving the performance of composites with all fiber types for the use in marine construction, such as increasing moisture and fire resistance. These research areas will be essential to develop composites that are stable and durable in the extreme conditions present in the marine environment. Further evaluations comparing the performance of these FRPCs with other commonly used construction materials such as steel or concrete may furthermore provide additional insight into the suitability and long-term effects of substituting such materials with FRPC components.

\section{Appendix}

For the presented evaluation, the scoring of the attributes is completed on a 5-point scale, 1 being the lowest and 5 the highest possible score. For each attribute, the values of 1, 3, and 5 were defined to represent the following scale:

1.Property or value below the level a material can be considered acceptable. 


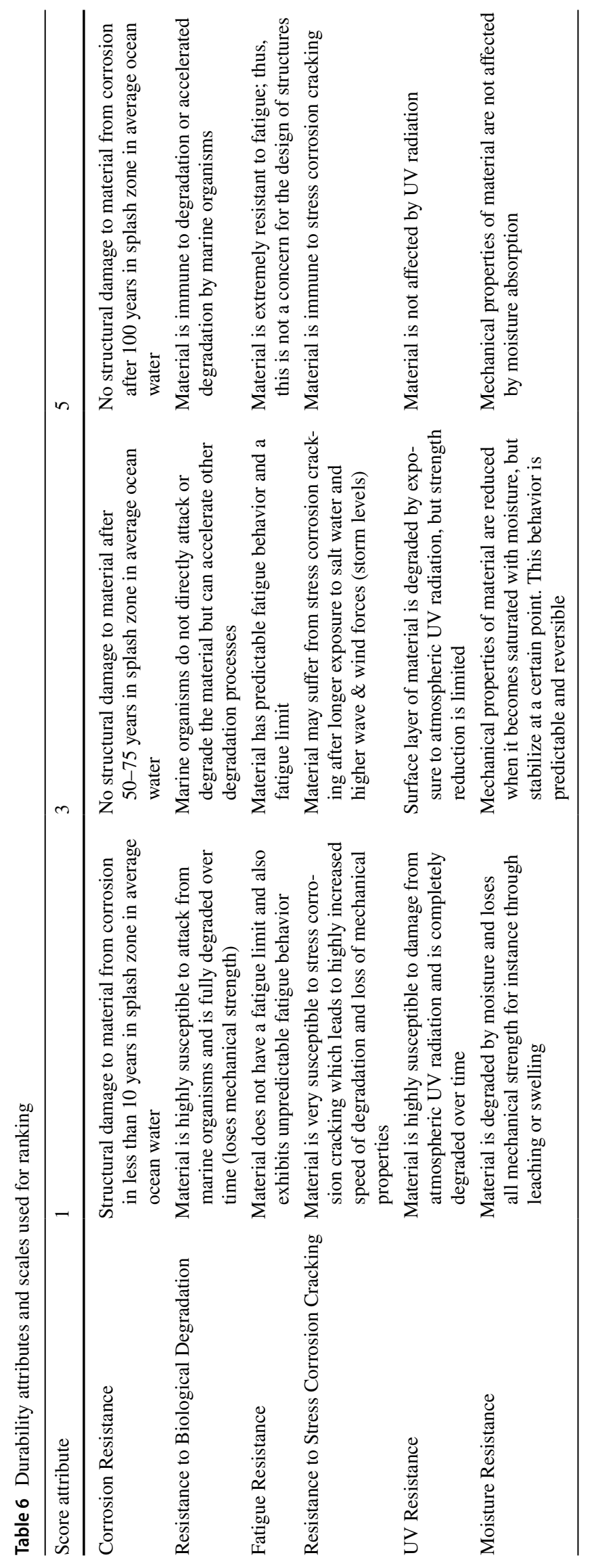









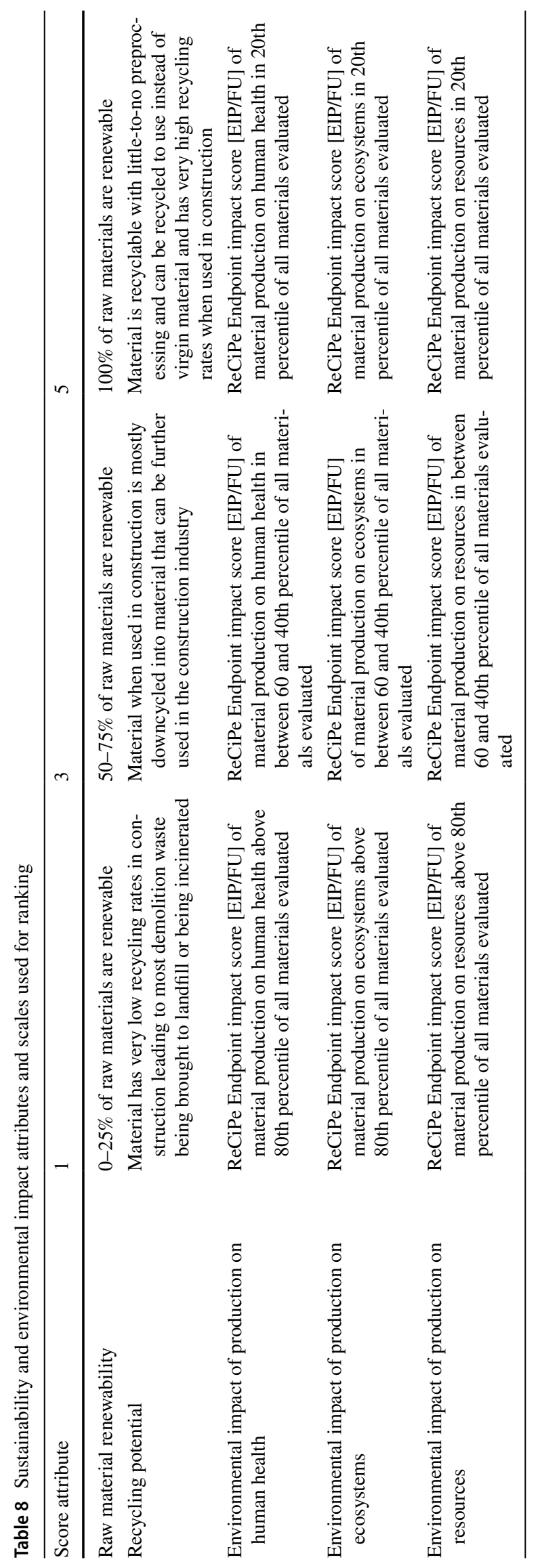




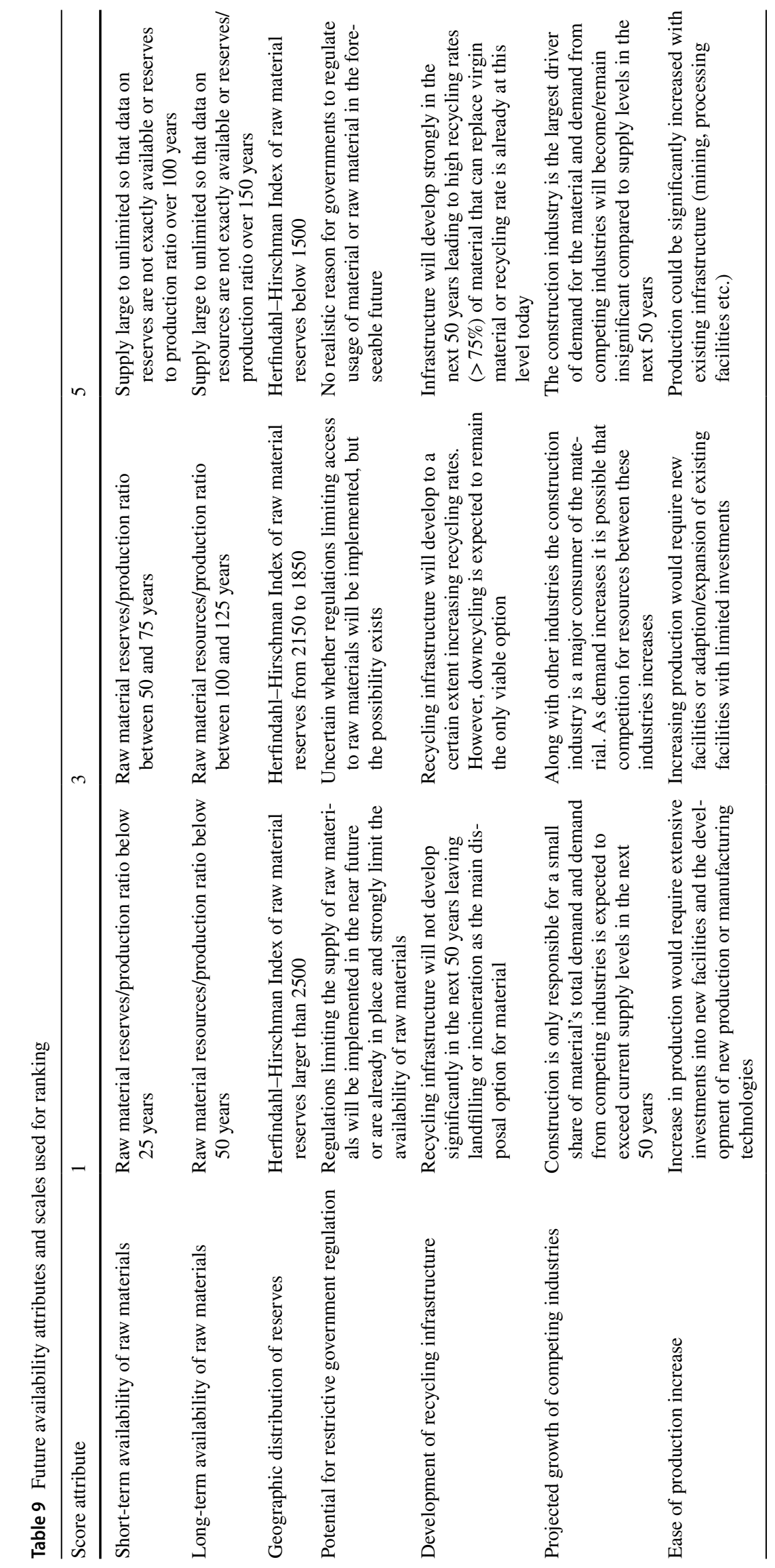


3.Property or value that can be seen as average for a material used in construction.

5.Property or value of a hypothetical ideal material.

The attributes included in the framework are either qualitative or quantitative. For the quantitative attributes, values were specified for the points along the scale. For the qualitative attributes, the requirements for each of the three mentioned points were described as precisely as possible. All attributes and their ranking scales are shown in Tables 6, 7,8 , and 9

Supplementary Information The online version contains supplementary material available at https://doi.org/10.1007/s40722-021-00187-x .

Funding Open Access funding provided by Universität Zürich. This research did not receive any specific grant from funding agencies in the public, commercial, or not-for-profit sectors.

\section{Compliance with ethical standards}

Conflict of interest The author(s) declare that they have no competing interests.

Open Access This article is licensed under a Creative Commons Attribution 4.0 International License, which permits use, sharing, adaptation, distribution and reproduction in any medium or format, as long as you give appropriate credit to the original author(s) and the source, provide a link to the Creative Commons licence, and indicate if changes were made. The images or other third party material in this article are included in the article's Creative Commons licence, unless indicated otherwise in a credit line to the material. If material is not included in the article's Creative Commons licence and your intended use is not permitted by statutory regulation or exceeds the permitted use, you will need to obtain permission directly from the copyright holder. To view a copy of this licence, visit http://creativecommons.org/licenses/by/4.0/.

\section{References}

Affolter C, Barbezat M, Piskoty G, Neuner O, Terrasi G (2018) Failure of a sag water pipe triggered by aging of the GFRP composite relining. Eng Fail Anal 84:358-370. https://doi.org/10.1016/j. engfailanal.2017.09.017

Alhuthali AM, Low I-M (2015) Effect of prolonged water absorption on mechanical properties in cellulose fiber reinforced vinyl-ester composites. Polym Eng Sci 55:2685-2697. https://doi.org/10. $1002 /$ pen.23617

Ashby MF (2016) Materials selection in mechanical design, 5th edn. Butterworth-Heinemann, Burlington

Azrague K, Inman MR, Alnæs LI, Schlanbusch RD, Jóhannesson B, Sigfusson TI, Thorhallsson ER, Franzson H, Arnason AB, Vares S (2016) Life cycle assessment as a tool for resource optimisation of continuous basalt fibre production in Iceland. In: Life Cycle Assessment and Other Assessment Tools for Waste Management and Resource Optimization, Professor Umberto Arena, Second University of Naples, Italy Professor Thomas Astrup, Denmark Technical University, Denmark Professor Paola Lettieri, University College London, United Kingdom Eds, ECI Symposium Series. https://dc.engconfintl.org/lca_waste/10
Bai J (ed) (2013) Advanced fibre-reinforced polymer (FRP) composites for structural applications. Woodhead publishing series in civil and structural engineering, no. 46. Woodhead Publication, Philadelphia

Berges M, Léger R, Placet V, Person V, Corn S, Gabrion X, Rousseau J, Ramasso E, Ienny P, Fontaine S (2016) Influence of moisture uptake on the static, cyclic and dynamic behaviour of unidirectional flax fibre-reinforced epoxy laminates. Compos A Appl Sci Manuf 88:165-177. https://doi.org/10.1016/j.compositesa.2016. 05.029

Bhat T, Fortomaris D, Kandare E, Mouritz AP (2017) Properties of thermally recycled basalt fibres and basalt fibre composites. J Mater Sci. https://doi.org/10.1007/s10853-017-1672-7

Colombo C, Vergani L, Burman M (2012) Static and fatigue characterisation of new basalt fibre reinforced composites. Compos Struct 94:1165-1174. https://doi.org/10.1016/j.compstruct.2011.10.007

Correia JR, Cabral-Fonseca S, Branco FA, Ferreira JG, Eusébio MI, Rodrigues MP (2006) Durability of pultruded glass-fiber-reinforced polyester profiles for structural applications. Mech Compos Mater 42:325-338. https://doi.org/10.1007/s11029-006-0042-3

Correia JR, Branco FA, Ferreira JG (2010) The effect of different passive fire protection systems on the fire reaction properties of GFRP pultruded profiles for civil construction. Compos A Appl Sci Manuf 41:441-452. https://doi.org/10.1016/j.compositesa. 2009.12.002

Correia JR, Bai Y, Keller T (2015) A review of the fire behaviour of pultruded GFRP structural profiles for civil engineering applications. Compos Struct 127:267-287. https://doi.org/10.1016/j. compstruct.2015.03.006

Das S, Warren J, West D, Schexnayder SM (2016) Global carbon fiber composites supply chain competitiveness analysis. United States. https://doi.org/10.2172/1260138

Davies P, Pomiès F, Carlsson LA (1996) Influence of water and accelerated aging on the shear fracture properties of glass/epoxy composite. Appl Compos Mater 3:71-87

Fang H, Bai Y, Liu W, Qi Y, Wang J (2019) Connections and structural applications of fibre reinforced polymer composites for civil infrastructure in aggressive environments. Compos B Eng 164:129-143. https://doi.org/10.1016/j.compositesb.2018.11.047

Figliolini AM, Carlsson LA (2013) Mechanical properties of vinylester resins exposed to marine environments. Polym Eng Sci 53:24132421. https://doi.org/10.1002/pen.23496

Figliolini AM, Carlsson LA (2014) Mechanical properties of carbon fiber/vinylester composites exposed to marine environments. Polym Compos 35:1559-1569. https://doi.org/10.1002/pc.22809

Fiore V, Scalici T, Di Bella G, Valenza A (2015) A review on basalt fibre and its composites. Compos B Eng 74:74-94. https://doi.org/ 10.1016/j.compositesb.2014.12.034

Fiore V, Calabrese L, Di Bella G, Scalici T, Galtieri G, Valenza A, Proverbio E (2016) Effects of aging in salt spray conditions on flax and flax/basalt reinforced composites: wettability and dynamic mechanical properties. Compos B Eng 93:35-42. https://doi.org/ 10.1016/j.compositesb.2016.02.057

Frigione M, Lettieri M (2018) Durability issues and challenges for material advancements in FRP employed in the construction industry. Polymers (Basel). https://doi.org/10.3390/polym10030 247

Garcia-Espinel JD, Castro-Fresno D, Parbole Gayo P, Ballester-Muñoz $F$ (2015) Effects of sea water environment on glass fiber reinforced plastic materials used for marine civil engineering constructions. Mater Des 66(66):46-50. https://doi.org/10.1016/j.matdes.2014. 10.032

Gassan J, Andrzej B (1999) Effect of cyclic moisture absorption desorption on the mechanical properties of silanized jute-epoxy composites. Polym Compos 20:604-611 
Graham-Jones J, Summerscales J (2015) Marine applications of advanced fibre-reinforced composites. Woodhead publishing series in composites science and engineering. Woodhead Publishing, Oxford. https://doi.org/10.1016/C2013-0-16504-X

Granta Material Intelligence (2018) MaterialUniverse materials data. http://www.grantadesign.com/products/data/materialuniverse. htm. Accessed 14 Nov 2018

Hertzberg T (2005) Dangers relating to fires in carbon-fibre based composite material. Fire Mater 29:231-248. https://doi.org/10. 1002/fam.882

Job S, Leeke G, Mativenga PT, Oliveux G, Pickering S, Shuaib NA (2016) Composites Recycling: Where are we now? Composites UK. https://compositesuk.co.uk/system/files/documents/Recyc ling\%20Report\%202016.pdf

Kappenthuler S, Seeger S (2019) From resources to research—a framework for identification and prioritization of materials research for sustainable construction. Mater Today Sustain 7:100009. https:// doi.org/10.1016/j.mtsust.2019.100009

Karbhari VM (2007) Fabrication, quality and service-life issues for composites in civil engineering. In: Karbhari VM (ed) Durability of composites for civil structural applications. Woodhead, Cambridge, pp 13-30

Kootsookos A, Mouritz AP (2004) Seawater durability of glass- and carbon-polymer composites. Compos Sci Technol 64:1503-1511. https://doi.org/10.1016/j.compscitech.2003.10.019

Kulkarni N, Mahfuz H, Jeelani S, Carlsson LA (2003) Fatigue crack growth and life prediction of foam core sandwich composites under flexural loading. Compos Struct 59:499-505

Latif M, Prabhakar MN, Song J (2019) Fabrication of hybrid matrix/ silane modified carbon fabric composites and study of their mechanical properties. J Appl Polym Sci 136:47695. https://doi. org/10.1002/app.47695

Le Duigou A, Davies P, Baley C (2009) Seawater ageing of flax/ poly(lactic acid) biocomposites. Polym Degrad Stab 94:11511162. https://doi.org/10.1016/j.polymdegradstab.2009.03.025

Liu Q, Shaw MT, Parnas RS, McDonnell A-M (2006) Investigation of basalt fiber composite aging behavior for applications in transportation. Polym Compos 27:475-483. https://doi.org/10.1002/ pc. 20215

Lucintel (2011) Opportunities in natural fiber composites. http://www. lucintel.com/lucintelbrief/potentialofnaturalfibercomposites-final. pdf. Accessed 13 Nov 2017

Maslinda AB, Abdul Majid MS, Ridzuan MJM, Afendi M, Gibson AG (2017) Effect of water absorption on the mechanical properties of hybrid interwoven cellulosic-cellulosic fibre reinforced epoxy composites. Compos Struct 167:227-237. https://doi.org/ 10.1016/j.compstruct.2017.02.023

Nguyen Q, Ngo T, Mendis P, Tran P (2013) Composite materials for next generation building façade systems. Civ Eng Archit 1:88-95

O'Dea N (2015) Emerging innovation trends in composites. [Conference Presentation] Composites engineering show, Birmingham, UK

Oliveux G, Dandy LO, Leeke GA (2015) Current status of recycling of fibre reinforced polymers: review of technologies, reuse and resulting properties. Prog Mater Sci 72:61-99. https://doi.org/10. 1016/j.pmatsci.2015.01.004

Pickering KL, Efendy MA, Le TM (2016) A review of recent developments in natural fibre composites and their mechanical performance. Compos A Appl Sci Manuf 83:98-112. https://doi.org/ 10.1016/j.compositesa.2015.08.038
Poodts E, Minak G, Zucchelli A (2013) Impact of sea-water on the quasi static and fatigue flexural properties of GFRP. Compos Struct 97:222-230. https://doi.org/10.1016/j.compstruct.2012. 10.021

Ramesh M, Palanikumar K, Reddy KH (2017) Plant fibre based biocomposites: sustainable and renewable green materials. Renew Sustain Energy Rev 79:558-584. https://doi.org/10.1016/j.rser. 2017.05.094

Ramirez FA, Carlsson LA, Acha BA (2008) Evaluation of water degradation of vinylester and epoxy matrix composites by single fiber and composite tests. J Mater Sci 43:5230-5242. https://doi.org/ 10.1007/s10853-008-2766-Z

Reuben RL (1994) Materials in marine technology. Springer, London

Seefeldt H (2012) Flame retardancy of wood-plastic composites. Zugl.: Berlin, Techn. Univ., Diss., 2012. BAM-Dissertationsreihe, vol 90. Bundesanstalt für Materialforschung und -prüfung (BAM), Berlin

Shahawy MA, Arockiasamy M, Beitelman T, Sowrirajan R (1996) Reinforced concrete rectangular beams strengthened with CFRP laminates. Compos B Eng 27B:225-233

Sun Z (2018) Progress in the research and applications of natural fiberreinforced polymer matrix composites. Sci Eng Compos Mater 25:835-846. https://doi.org/10.1515/secm-2016-0072

Tual N, Carrere N, Davies P, Bonnemains T, Lolive E (2015) Characterization of sea water ageing effects on mechanical properties of carbon/epoxy composites for tidal turbine blades. Compos A Appl Sci Manuf 78:380-389. https://doi.org/10.1016/j.compo sitesa.2015.08.035

Uomoto T, Mutsuyoshi H, Katsuki F, Misra S (2002) Use of fiber reinforced polymer composites as reinforcing material for concrete. J Mater Civ Eng 14:191-209

van Vuure AW, Baets J, Wouters K, Hendrickx K (2015) Compressive properties of natural fibre composites. Mater Lett 149:138-140. https://doi.org/10.1016/j.matlet.2015.01.158

Wei B, Cao H, Song S (2011) Degradation of basalt fibre and glass fibre/epoxy resin composites in seawater. Corros Sci 53:426-431. https://doi.org/10.1016/j.corsci.2010.09.053

Witten E, Kraus T, Kühnel M (2016) Composites market report 2016. AVK. https://eucia.eu/userfiles/files/20161128_market_report_ 2016_english.pdf

Wu Y, Xia C, Cai L, Garcia AC, Shi SQ (2018) Development of natural fiber-reinforced composite with comparable mechanical properties and reduced energy consumption and environmental impacts for replacing automotive glass-fiber sheet molding compound. J Clean Prod 184:92-100. https://doi.org/10.1016/j.jclepro.2018.02.257

Yan L, Chouw N, Jayaraman K (2014) Flax fibre and its compositesa review. Compos B Eng 56:296-317. https://doi.org/10.1016/j. compositesb.2013.08.014

Yan L, Chouw N, Jayaraman K (2015) Effect of UV and water spraying on the mechanical properties of flax fabric reinforced polymer composites used for civil engineering applications. Mater Des 71:17-25. https://doi.org/10.1016/j.matdes.2015.01.003

Publisher's Note Springer Nature remains neutral with regard to jurisdictional claims in published maps and institutional affiliations. 